\title{
Study on Dynamic Characteristics of Deep Siltstone under High Static Stress and Frequent Dynamic Disturbance
}

\author{
Lu-ping Cheng $\mathbb{D},{ }^{1}$ Chun Wang $\mathbb{D},{ }^{1,2,3,4}$ Li-zhong Tang, ${ }^{3}$ Cheng Wang $\mathbb{D}^{1,4}$ \\ Zhu-qiang Xiong, ${ }^{1,4}$ Shi-ming Wei, ${ }^{1,4}$ Yuan Chen, ${ }^{3}$ Tao Liu, ${ }^{3}$ and Yong-heng Wei ${ }^{3}$ \\ ${ }^{1}$ School of Energy Science and Engineering, Henan Polytechnic University, Jiaozuo, Henan 454000, China \\ ${ }^{2}$ State and Local Joint Engineering Laboratory for Gas Drainage \& Ground Control of Deep Mines, Henan Polytechnic University, \\ Jiaozuo, Henan 454000, China \\ ${ }^{3}$ School of Resources and Safety Engineering, Central South University, Changsha, Hunan 410083, China \\ ${ }^{4}$ The Collaborative Innovation Center of Coal Safety Production of Henan, Jiaozuo, Henan 454000, China
}

Correspondence should be addressed to Lu-ping Cheng; 775174918@qq.com, Chun Wang; wangchun@hpu.edu.cn and Cheng Wang; wangcheng@hpu.edu.cn

Received 14 March 2019; Revised 23 June 2019; Accepted 9 July 2019; Published 22 July 2019

Academic Editor: Wensu Chen

Copyright $\odot 2019$ Lu-ping Cheng et al. This is an open access article distributed under the Creative Commons Attribution License, which permits unrestricted use, distribution, and reproduction in any medium, provided the original work is properly cited.

The mechanical characteristics of siltstone under high static load and frequent dynamic disturbance were investigated by the improved split Hopkinson pressure bar (SHPB), which is used to simulate the failure phenomenon of the extracted ore drift owing to high stress concentration and blasting disturbance in Dongguashan copper mine at the depth of more than $900 \mathrm{~m}$. The maximum dynamic strain, dynamic stress, and dynamic deformation modulus of rock of each impact were researched to provide theoretical basis for mining production. The results show that the dynamic stress-strain curves of siltstone before the peak stress present two characteristics of linear and nonlinear variation and different degrees of resilience after the peak stress under high static stress and frequent dynamic disturbance. The strain rate rises in a linear trend with the increasing times of dynamic disturbance, but the value of the strain rate is approximately constant in the process of one impact. With the increase of the strain rate, the maximum dynamic strain rises at the same static stress, while the peak dynamic stress and dynamic deformation modulus decrease linearly. Because the inner stored elastic energy of rock determines the value of resilient strain after unloading, the elastic energy may increase with the increase of static axial stress in a certain range and then the resilient strain increases. Accumulative times of dynamic disturbance and static axial stress show the relationship that the former is obviously reduced with the increase of the later.

\section{Introduction}

With the rapid development of science and technology and the increase of large deep rock engineering, the mechanical characteristics of deep rock mass under complex mechanical environment have been a frontier issue in today's world $[1,2]$. Actually, domestic and foreign scholars have made remarkable achievements aimed at the issue with a large number of experimental studies. For example, the SHPB test device was improved by $\mathrm{Li}$ et al., and they also used the device to complete the test of static-dynamic coupling loading of the rock under the high strain rate [3-5]. This provides the experimental equipment foundation for the research of the dynamic characteristics of deep siltstone under high static stress and frequent dynamic disturbance. Some scholars have studied the failure mode of rocks under static-dynamic coupling loading, which provides a reference basis for determining the moment of the ultimate instability failure of rocks in this research. For example, Yin et al. [6-8] investigated the failure mode of the rock under static-dynamic coupling loading by the same device. The results show that the failure mode of rock samples under the combined load of static and dynamic is affected by preload axial compression and impact load, and the failure type is " $\mathrm{V}$ " or "X." The study also found that the failure modes of rock samples are combined shear failure or tensile failure when 
the impact load energy is low, but the failure modes of rock samples become tensile failure when the impact load energy is high. And the failure size of the rock sample is uniform when the preloading static load is low, but the failure size of the rock sample is a great disparity when the preloading static load is high. The above research results lay a foundation for determining the failure mode of rock samples under high static stress and frequent dynamic disturbance. $\mathrm{Ma}$ et al. [9-14] analyzed deformation, strength characteristics, failure mode, and energy dissipation of the rock by the experimental studies on sandstone of comparatively better integrity and uniformity under unidimensional, two-dimensional, or three-dimensional high stress and dynamic loading. It is found that the dynamic compressive strength and energy consumption of rocks increase with the increase of preload axial compression or the ratio of axial pressure to confining pressure. And the specimen radius has direct correlation with the test result, and the diameter of the rock sample selected in the dynamic test results in different deformations and failure characteristics. The damage of rock samples is more serious, and the deformation of rock samples is more discrete when the specimen radius is larger. The above research results provide references for the selection of rock sample diameter and the analysis of dynamic mechanical properties in the dynamic test. There are some scholars who have also conducted researches on the mechanical properties of rocks under static, dynamic, and static combined loads. For instance, Kinoshita et al. [15, 16] proposed and fixed a constitutive model of rock, which is suitable for the dynamic load. Green et al. [17-21] indicated that the mechanical properties of rock show great differences when the rock is subjected to static load, dynamic load, or static-dynamic coupling load through the theoretical research and experimental results. Du et al. [22-24] have studied the changing rules of the dynamic and static characteristics of rock, which took into account the shape, interface, and internal and external forces of hollow rock samples. Based on the sample shape factor, some equations were proposed for calculating rock strength. It was found that the triaxial compressive strength of hollow rock increases with the increase of external pressure. These research works reveal that the mechanical characteristics of rocks are different with the different mechanical environments, which further indicates that it is of certain significance to study the dynamic characteristics of deep rock under high static stress and frequent dynamic disturbance.

The progress and safety of rock mass engineering construction are directly affected by the mechanical characteristics of rock under high static stress and frequent dynamic disturbance. Therefore, theoretical analysis, rock dynamics test, numerical simulation, and other methods are used by scholars to study the dynamic characteristics of deep rocks. Cheng and Yang [25], Tan et al., [26] and Tao et al. [27] discussed the variety of peak stress, peak strain, and elastic modulus with the increasing dynamic disturbance times and investigated dynamic characteristics of skarn under high static stress and frequent dynamic disturbance. Yin et al. [6] found that high axial pressure and confining pressure were of great significance to the failure mode of rock with impact disturbance. Manouchehrian and Cai [28], $\mathrm{Li}$ et al. [29], and $\mathrm{Hu}$ et al. [30] have studied the rockbursts near fault regions in deep tunnels under static and dynamic loads, the velocity and the released kinetic energy of failed rocks, the failure zone around the tunnel, and the deformed mesh were presented and used to identify stable and unstable rock failures. At the same time, it is found that the dynamic damage of the roof and floor of the deep buried tunnel is more likely to occur under the disturbance of the blasting load. The above research provides engineering background and theoretical basis for the research of the dynamic characteristics of deep rock. The numerical simulation method was used by Zhu et al. [31-34] to study the damage mechanism, fracture mode, and failure characteristics of rocks under frequent dynamic disturbance. It was found that dynamic disturbance is one of the most important factors to trigger rockbursts in deep rock mass. It is also proved that the homogeneity of rock is a nonnegligible index when the numerical simulation method is used to predict the dynamic strength of deep rock. Li et al. [35] and Wang et al. [36] further explored the failure characteristics of coal and rock mass under frequent dynamic disturbance and found that the dynamic strength of saturated coal increases with the increase of confining pressure and is more obvious than that of natural coal. The above research further indicates that the research of this topic has certain guiding significance to engineering practice. In a word, although the mechanical characteristics of rock under impact load have made a certain degree of achievements, the research on dynamic characteristics of deep rock involves less in the circumstances of high static stress and frequent dynamic disturbance.

The method of open stope mining with delayed filling is adopted to deep ore body in Dongguashan copper mine, and part of the extracted ore drift is located in the silt sandstone. According to the combined action of high stress concentration and frequent dynamic disturbance, surrounding rock of the stope bottom structure is destroyed seriously. In reality, using concentrated stress and blasting disturbance effectively to exploit the deep ore body or avoid a series of disadvantage is an urgent problem that needs to be solved in Dongguashan copper mine presently. Therefore, the study on the mechanical properties of rock under high static stress and frequent dynamic disturbance is of great significance to practical engineering.

\section{Test Condition and Scheme}

2.1. Rock Specimens. The specimens of siltstone used in the test were drilled at the depth of more than $900 \mathrm{~m}$ in Dongguashan copper mine, and the selected site is located in the extracted ore drift of the ore body footwall. The surface of the compact rock core with no obvious microcracks should be a first choice. In order to ensure the accuracy of test data, all test specimens were processed strictly in accordance with rock mechanical testing requirements. So, the specimens were made with the dimensions of $50 \mathrm{~mm} \times 50 \mathrm{~mm}$, and the no parallelism and the no perpendicularity were both less than $0.02 \mathrm{~mm}$ by means of polishing at both ends carefully. 
Due to the effect of transverse inertia, the elastic wave generates dispersion when the elastic wave propagates in the slender bar. $\mathrm{Li}$ and $\mathrm{Gu}$ [37] found that the dispersion effect of waves could be reduced by adjusting the length-diameter ratio of rock samples. At the same time, the inertia effect is serious when the rock sample is too long, and the end effect is too large when the rock sample is too short. The rock sample, the incident bar, and the transmission bar were subjected to impact loading with the same area in the impact disturbance test, so the diameter of the rock sample is equal to the diameter of bar, and it is $50 \mathrm{~mm}$. Finally, the rock sample length-diameter ratio of the impact disturbance test was $1: 1$; namely, the size of the rock sample was $50 \mathrm{~mm} \times 50 \mathrm{~mm}$.

2.2. Test Equipment. The test equipment based on the improved SHPB device can successfully provide both static pressure and dynamic pressure at the medium-to-high rate, and the structure diagram is shown in Figure $1[38,39]$. The test system is mainly composed of heterotype impact hammer, incident bar, transmission bar, buffer bar, pressure loading unit, and oscilloscope. The material quality of heterotype impact hammer, incident bar, transmission bar, and buffer bar is $40 \mathrm{Cr}$ alloy steel of high strength, the longitudinal wave velocity is $5547 \mathrm{~m} / \mathrm{s}$, the density is $7.8 \mathrm{t} / \mathrm{m}^{3}$, the elastic modulus is $240 \mathrm{GPa}$, and the uniaxial compressive strength is $800 \mathrm{MPa}$. The heterotype impact hammer is placed in a conical bullet to obtain a stable halfsine wave loading and eliminate the oscillation. The diameter of the specimen is the same as that of the input bar or output bar, and the loading wave is a half-sine wave under the approximate constant strain rate [37, 40,41]. The data of each test are collected by the DL-750 oscilloscope and CS-1D ultradynamic stain gauge.

In this test, the value of loaded static stress can be controlled by the hand-actuated oil hydraulic pump, and the loading rate remains $0.5 \mathrm{MPa} / \mathrm{s}$. In addition, the impact air pressure can be adjusted by the amount of nitrogen in the punch device of launch, and the specific physical diagram about the loading device of static axial stress and the generating device of impact air pressure is shown in Figure 2.

2.3. Test Principle. In Figure 1, the incident strain and reflected strain signal were measured by strain gauge $A_{1}$, while the transmission strain signal was measured by strain gauge $A_{2}$. Based on the hypothesis that propagation of elastic waves in a slender rod under one-dimensional stress is undistorted, the dynamic stress, strain rate, and strain formula of the sample are as follows [37, 41]:

$$
\begin{aligned}
& \sigma_{\mathrm{s}}(t)=\frac{A}{2 A_{\mathrm{S}}}\left[\sigma_{\mathrm{I}}(t)+\sigma_{\mathrm{R}}(t)+\sigma_{\mathrm{T}}(t)\right], \\
& \dot{\varepsilon}_{\mathrm{s}}(t)=\frac{C}{E l}\left[\sigma_{\mathrm{T}}(t)+\sigma_{\mathrm{R}}(t)-\sigma_{\mathrm{I}}(t)\right],
\end{aligned}
$$

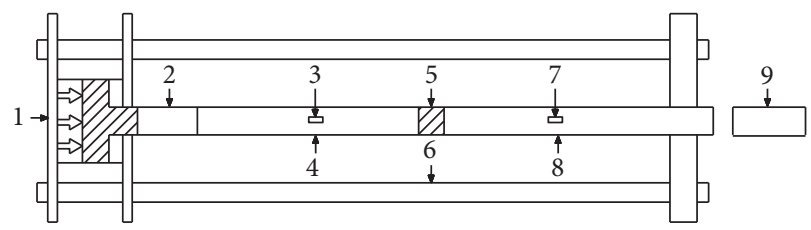

FIgURE 1: Structure diagram of the system with coupled static and dynamic loads. 1, pressure loading unit; 2, buffer bar; 3 , strain gauge $A_{2} ; 4$, transmission bar; 5 , rock specimen; 6 , support; 7 , strain gauge $A_{1} ; 8$, incident bar; 9 , heterotype impact hammer.

$$
\varepsilon_{\mathrm{s}}(t)=\frac{C}{E l} \int_{0}^{t}\left[\sigma_{\mathrm{T}}(t)+\sigma_{\mathrm{R}}(t)-\sigma_{\mathrm{I}}(t)\right] d t,
$$

where $\sigma_{\mathrm{I}}(t), \sigma_{\mathrm{R}}(t)$, and $\sigma_{\mathrm{T}}(t)$ are the incident stress, reflected stress, transmitted stress at $t$ of the impact process, respectively; $\sigma_{\mathrm{s}}(t), \dot{\varepsilon}_{\mathrm{s}}(t)$, and $\varepsilon_{\mathrm{s}}(t)$ are the dynamic stress, strain rate, and strain of the specimen, respectively; $A$ is the cross-sectional area of the elastic bar; $A_{\mathrm{S}}$ is the cross-sectional area of the specimen; $E$ is the elastic modulus of the bar; $C$ is the wave velocity of the elastic bar; and $l$ is the length of the specimen.

2.4. Test Scheme. The main purpose of the experiment is to study the dynamic characteristics of deep siltstone under the combined action of high static stress and frequent dynamic disturbance. The high axial stress of the reserved point column in deep mining can be simulated by high prestatic stress in test with the axial pressure loading device, while the small disturbance of blasting excavation of rock can be simulated by the impact of the heterotypic impact hammer driven with air pressure. In order to determine the value of prestatic axial pressure, the British Instron 1346 electroservo controlled testing machine was utilized to conduct the uniaxial compressive strength test, and the test results are shown in Table 1.

For simulating the condition of high static stress, the specimen is required to bear the static stress which approaches the value of static peak strength of rock as far as possible. However, there is large discreteness of test data and heterogeneity of the rock structure from Table 1, so the highest static stress is $65 \mathrm{MPa}$ to guarantee the test effectiveness with a limited number of specimens. In order to ensure specimens can withstand repeated impact and the stress distribution is in accordance with practical engineering, the prestatic axial compressive stress value is $35 \mathrm{MPa}, 45 \mathrm{MPa}, 55 \mathrm{MPa}$, and $65 \mathrm{MPa}$, respectively, which corresponds to the value of $44.85 \%, 57.67 \%, 70.49 \%$, and $83.30 \%$ of uniaxial compressive strength. In this test, the minimum impact air pressure is selected to simulate frequently dynamic disturbance, namely, $0.4 \mathrm{MPa}$. Before the impact test, the two ends of the rock sample were buttered, and then the heterotype impact hammer was placed in a fixed position in the launching chamber. The oscilloscope is used to record test data in the process of each impact, and the prestatic axial stress must adjust after each impact and then the above operation is repeated until the specimen is completely broken. The specific test model of loading mechanic is shown in Figure 3. 


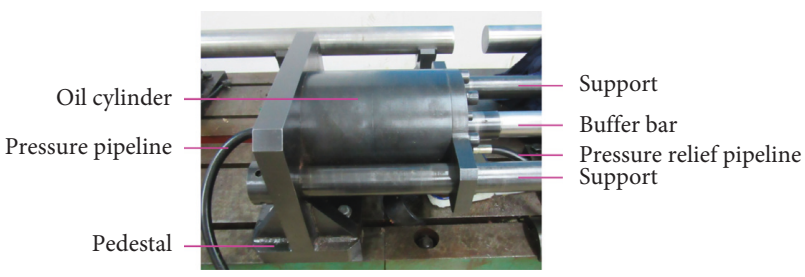

(a)

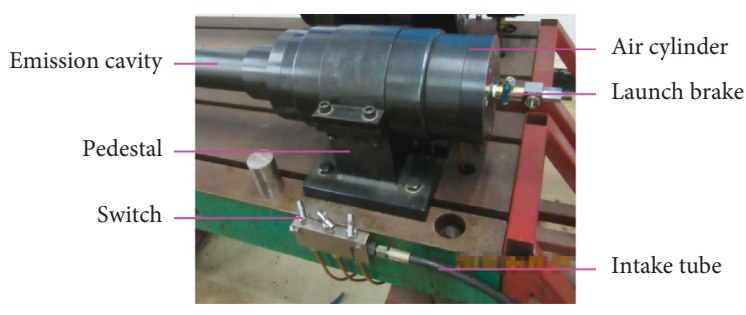

(b)

Figure 2: The physical map of the (a) pressure loading unit and (b) punch launcher.

TABLE 1: Results of impact in the uniaxial compressive strength test.

\begin{tabular}{lccccc}
\hline Specimen number & $L(\mathrm{~mm})$ & $D(\mathrm{~mm})$ & $\rho\left(\mathrm{g} / \mathrm{cm}^{3}\right)$ & Peak load $(\mathrm{kN})$ & Uniaxial compressive strength $(\mathrm{MPa})$ \\
\hline 1 & 81.97 & 42.19 & 2.73 & 43.64 & 31.23 \\
2 & 81.66 & 41.51 & 2.68 & 49.44 & 36.55 \\
3 & 81.61 & 42.07 & 2.67 & 174.15 & 125.35 \\
4 & 81.44 & 41.42 & 2.64 & 147.25 & 109.34 \\
5 & 81.43 & 41.29 & 3.10 & 95.52 & 71.37 \\
6 & 81.64 & 41.41 & 2.85 & 126.96 & 94.32 \\
Average & 81.63 & 41.65 & 2.78 & 106.16 & 78.03 \\
\hline
\end{tabular}
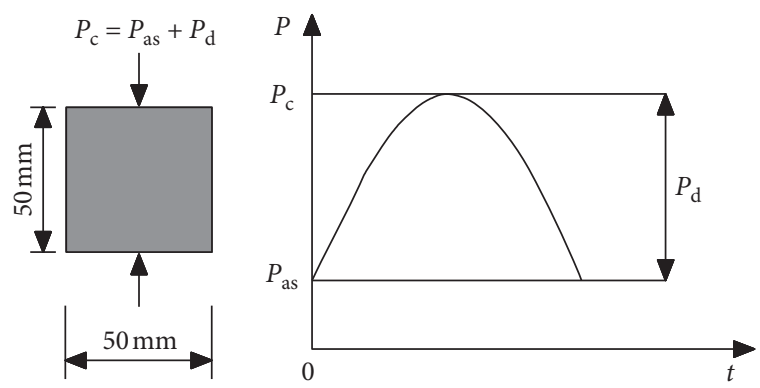

Figure 3: Model sketch of the test load. $P_{\mathrm{c}}$, total load; $P_{\mathrm{as}}$, static load; $P_{\mathrm{d}}$, impact load.

\section{Experimental Results and Analysis}

3.1. Experimental Results. During the test, the strain signal was measured by the strain gauge on the incident bar and transmission bar, and the stress-time curve is drawn as Figure 4 . The stress signal was converted into the incident stress, reflection stress, and transmission stress. Mechanical parameters of rock were calculated according to formulas (1)-(3).

In the impact test, the rock sample was installed between the incident bar and the transmission bar, and the impact signal was generated inside the sample when the incident bar was in contact with the rock sample at the same cross section under impact load. At this moment, the stress equilibrium between incident, transmitted, and reflected waves can be verified by the stress wave signal. Figure 4(b) shows the stress-time curve of rock sample ss1-3 under high static stress and dynamic impact load. The amplitude of the incident wave is basically equal to the amplitude of the transmitted wave in Figure 4(b), and it indicates that the stress wave is balanced during the impact test.

Figure 4 shows that the waveform of the incident wave is basically consistent, while the waveform of the reflected wave is different. At the same time, the transmitted wave decreases with the increasing dynamic disturbance times. The main reason for this is that although each impactive air pressure is constant, the contact surface between the specimen and incident bar is different, as well as the internal integrity. The reason for the difference in contact is that the damage degree of rock samples is different after each impact disturbance. The number and length of crack on the end face of the rock sample increase with the increase of impact times. Therefore, the contact surface between the specimen and incident bar is different.

The test data were processed in the light of the above principle, and the processed results are shown in Table 2 and Figure 5. The number, prestatic axial pressure, static stress, and accumulative impact times of final failure of each specimen are presented in Table 2 under dynamic disturbance. However, because there are a number of impact times of each specimen, in order to make the curves more clear, only part of dynamic stress-strain curves is drawn in Figure 5 in the way of approximately the same space between adjacent curves. The numbers on curves represent impact disturbance times.

In Table 2, the accumulative impact times refer to the total number of disturbance impacts on rock samples when the rock samples were under high static load. In this paper, the macroscopic failure state of the rock sample in the dynamic test is defined as the state that the rock sample cannot withstand both in high static load and impact disturbance. The macroscopic failure of rock samples occurred during impact or occurred under the action of prehigh static load after impact, and these are considered to be the ultimate failure state of rock samples in the dynamic test. After the impact disturbance, there is a state in which the rock sample cannot withstand the axial high static load, and the state can be defined as the state of the macroscopic failure occurred under impact. 


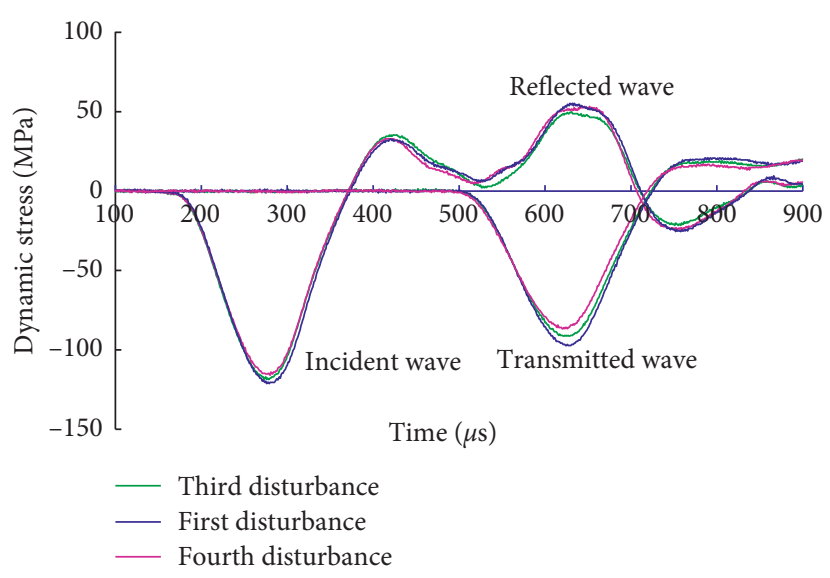

(a)

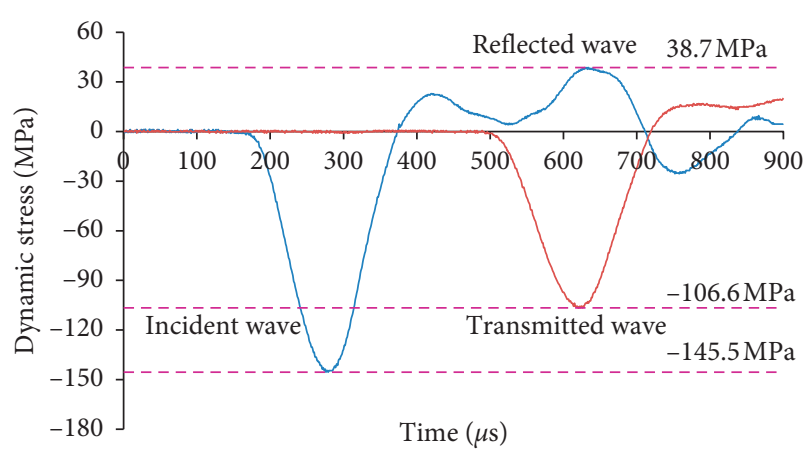

(b)

Figure 4: The stress-time curve of the impact test. (a) The typical stress-time curves of rock sample under the combined action of $65 \mathrm{MPa}$ axial static load and disturbance impact. (b) The stress-time curve of rock sample ss1-3 under high static stress and dynamic impact load (the second impact).

TABle 2: Accumulative impact times under a different static stress in test.

\begin{tabular}{lcc}
\hline $\begin{array}{l}\text { Specimen } \\
\text { number }\end{array}$ & Static stress $(\mathrm{MPa})$ & $\begin{array}{c}\text { Accumulative } \\
\text { impact times }\end{array}$ \\
\hline ss1-1 & 35 & 28 \\
ss1-2 & 35 & 21 \\
ss1-3 & 35 & 25 \\
Average & 35 & 25 \\
\hline ss2-1 & 15 & 45 \\
ss2-2 & 18 & 45 \\
ss2-3 & 20 & 45 \\
Average & 18 & 45 \\
\hline ss3-1 & 55 & 10 \\
ss3-2 & 55 & 8 \\
ss3-3 & 55 & 11 \\
Average & 55 & 10 \\
\hline ss4-1 & 65 & 3 \\
ss4-2 & 65 & 6 \\
ss4-3 & 65 & 5 \\
Average & 65 & 5 \\
\hline
\end{tabular}

3.2. Characteristics of Dynamic Deformation. Figure 5 shows that the dynamic stress rises with the increasing dynamic strain before the peak dynamic stress under the condition of a certain static axial stress but in two types of rise trends of the dynamic stress under the conditions of a different constant axial static stress. The stress exhibits a nonlinear relation of dynamic strain under the static axial stress of $35 \mathrm{MPa}, 45 \mathrm{MPa}$, and $65 \mathrm{MPa}$, but the relation between stress and strain is linear under the static axial stress of $55 \mathrm{MPa}$. The main reason for the nonlinear relationship is that both the elastic deformation and plastic deformation produce in the specimen in the process of dynamic impact, and comparatively, the reason for linear relation is that the elastic deformation produce only.

Dynamic stress-strain curves appear in different degrees of resilience after peak dynamic stress. In the dynamic impact loading stage, the specimen stores elastic energy in its internal with elastic deformation, so the loaded dynamic stress decreases after dynamic peak stress; when it is less than the internal stored elastic stress of the specimen, part of strain is recovered after dynamic peak stress, which means there is a resilient strain.

3.3. Variation Law of Strain Rate. It is difficult to measure the strain rate of the specimen directly in the process of experiment under high static load and frequent dynamic disturbance. According to the research of Zuo et al. [42], there is a linear relationship between the rock strain rate and loading rate under combined dynamic and static loading. They are also proved that strain rate and loading rate play an equal role in characterizing the mechanical properties of rock materials under combined loading. Therefore, it is feasible to infer the strain rate of the specimen by surveying the loading rate. Because dynamic strain rate is the time derivative about dynamic strain, the laws of the strain rate can be acquired by studying the dynamic strain during impact.

Figure 6 draws several groups of typical dynamic straintime curves of siltstone in the static axial stress of $35 \mathrm{MPa}$, and the figures on curves represent label numbers of impact disturbance. This figure shows that dynamic strain slowly reaches a maximum at first and then deceases gradually with the time. According to dynamic strain-time curves, the maximum strain of the specimen occurs at the stage of the time dropping from $140 \mu$ s to $160 \mu$ s in the process of each dynamic disturbance. This feature indicates that the deformation may be companied with germination and propagation of microcracks in rock. When the dynamic stress decreases to the preexisted static stress in specimen, the specimen instantaneously presents a steady state in the first place and then the deformation begins to recover; that is, the phenomenon of resilience appears after the peak dynamic stress-strain curve. Therefore, there is a decreasing phenomenon of dynamic strain in the late stage of dynamic strain-time curves. 


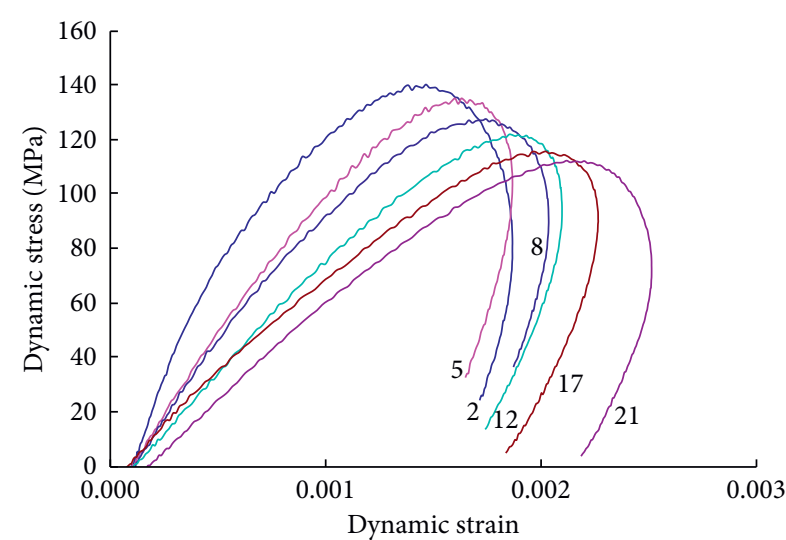

(a)

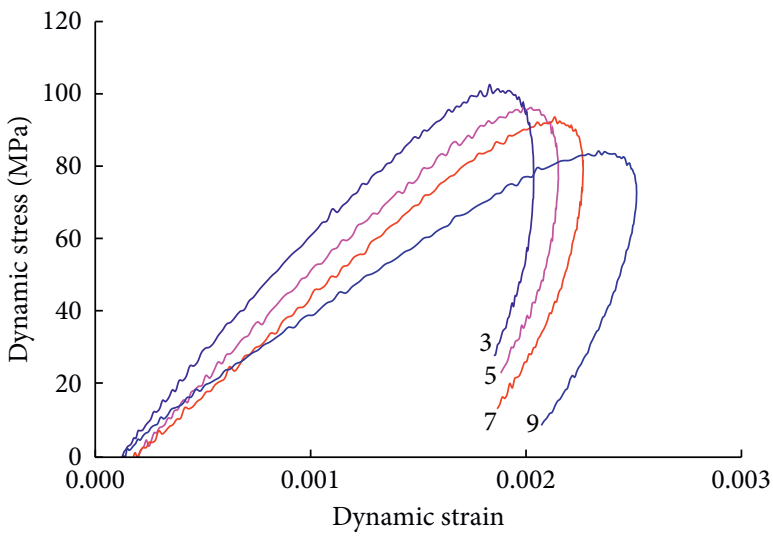

(c)

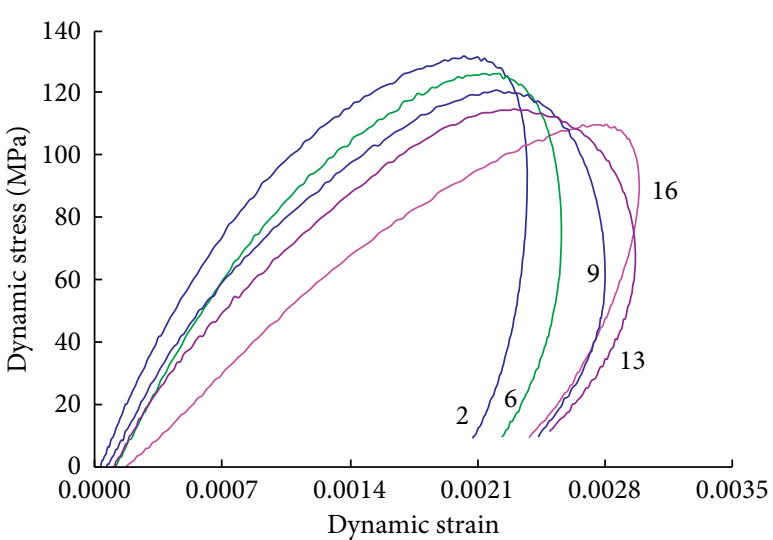

(b)

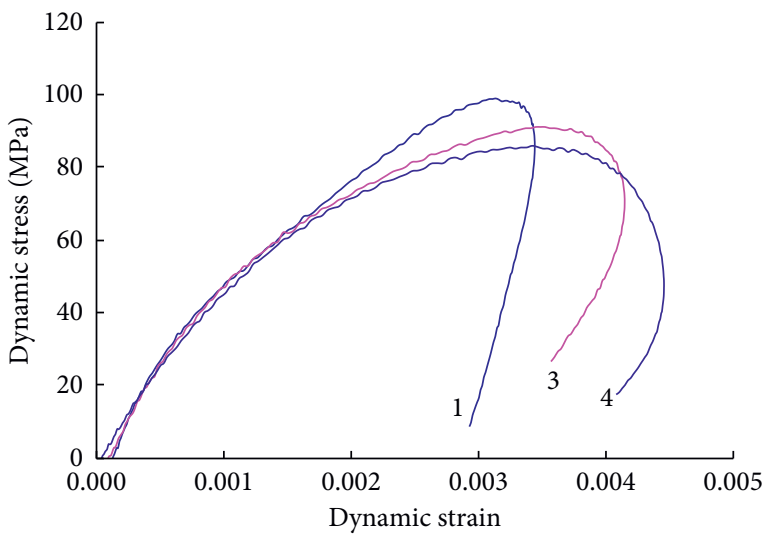

(d)

FIGURE 5: Dynamic stress-strain curves of siltstone under static stress and frequent impact disturbance. Static axial stress: (a) $35 \mathrm{MPa}$ (specimen number: ss1-3); (b) $45 \mathrm{MPa}$ (specimen number: ss2-2); (c) $55 \mathrm{MPa}$ (specimen number: ss3-1); (d) $65 \mathrm{MPa}$ (specimen number: ss4-3).

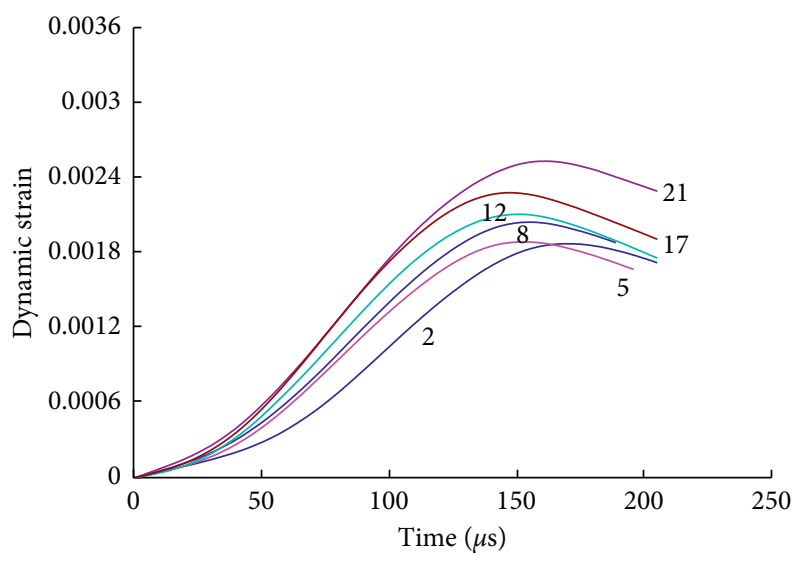

FIgure 6: The change law of dynamic strain with different impact times under the axial stress of $35 \mathrm{MPa}$.

Figure 6 also shows that there is an obvious linear growth of dynamic stress-strain curves before dynamic peak strain. And the slope of this straight line is a constant, namely, strain rate of specimen on the basis of the loaded principle of constant strain rate. Thus, the strain rate of specimen can be obtained indirectly under each dynamic disturbance. The relationship between strain rate and impact times under the corresponding static axial stress is drawn in Figure 7.

Figure 7 shows that the strain rate rises linearly with the increase of impact times. Because the strain rate is the time derivative of the corresponding dynamic strain, the enlargement of the strain rate presents the increase of deformation in unit time. In the dynamic load produced by a certain air pressure, the strain gradually increases with the increasing impact times, which indicates that the speed of microcracks of germination, branch, extension, and connection in specimen becomes faster and the damage of rock becomes more serious. The ability of resisting external disturbance reduces further and finally the specimen breaks.

3.4. Law of Maximum Strain and Resilient Strain. Figure 8 is a typical dynamic stress-strain curve with resilience strain. To make it clear to analyze dynamic parameters, some dynamic parameters are defined as follows. In the process of one impact, the maximum dynamic stress and strain are defined as peak dynamic stress, $\sigma_{\max }$, and maximum strain, $\varepsilon_{\max }$, respectively; after the impact, the finally nonrecoverable strain is defined as residual strain, $\varepsilon_{z}$, and the recovery strain is resilient strain, $\varepsilon_{h}$ : 


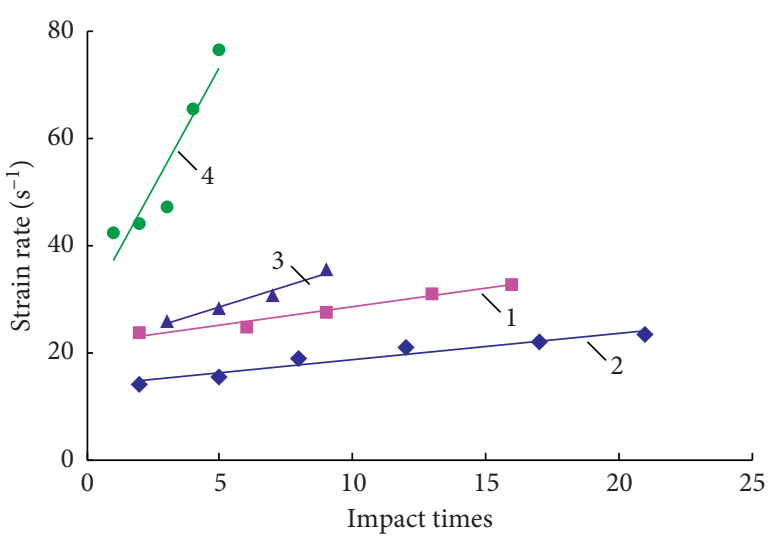

FIGURE 7: Relation between strain rate and impact times. 1, axial stress $35 \mathrm{MPa}$; 2, axial stress $45 \mathrm{MPa}$; 3 , axial stress $55 \mathrm{MPa}$; 4 , axial stress $65 \mathrm{MPa}$.

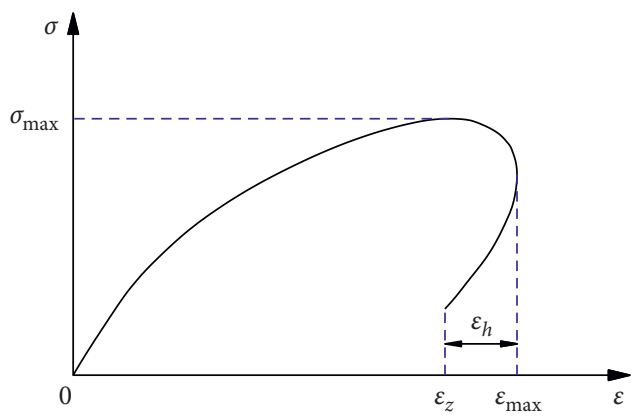

FIgURE 8: The sketch diagram of the mechanical parameter to dynamic stress-strain curves.

$$
\varepsilon_{h}=\varepsilon_{\max }-\varepsilon_{z}
$$

Figure 9 shows the relationship between the maximum strain and strain rate under different high static stress and frequent dynamic disturbance. When the static axial pressure is invariable, the maximum strain rises with the increasing strain rate. Therefore, it can be considered that increasing strain rate intensifies the germination, extension, and connection of microcracks and aggravates the damage of rock, leading to the reduction of resistance of rock to external impact.

Figure 9 also shows that strain rate increases on the whole with the increasing static axial pressure, as well as the maximum strain. Consequently, high static prepressure intensifies the damage in the specimen, so it is easier for dynamic disturbance to cause the branch, extension of original microcracks, and germinate new microcracks under high static stress.

Figure 10 is the regularity of resilient strain and strain rate, which shows that resilient strain increases with the increase of the strain rate, when the static axial stress is $35 \mathrm{MPa}, 45 \mathrm{MPa}$, and $55 \mathrm{MPa}$, respectively. It indicates that the original microcracks branch and extend in a small degree, so the macroscopical destruction has not happened yet at these static axial compressions. Generally speaking, the stored elastic energy in specimen increases with the increasing strain rate,

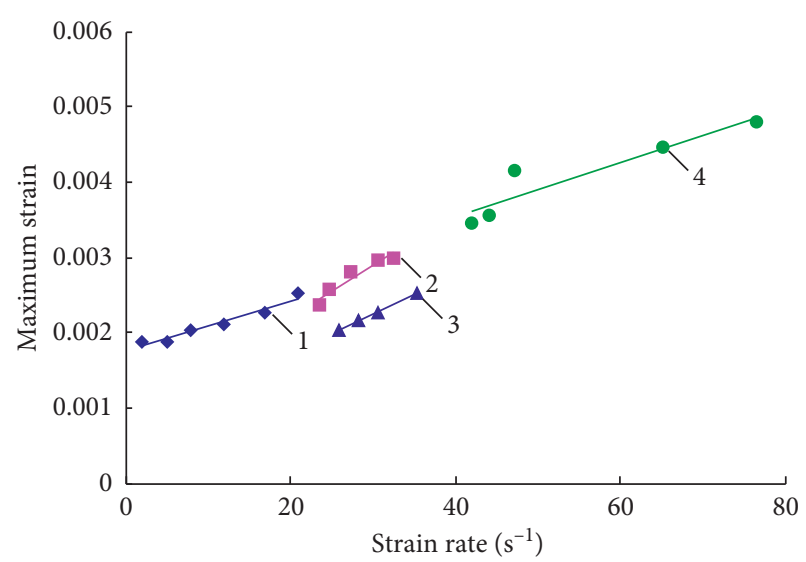

Figure 9: Relation between the maximum strain and strain rate. 1, axial stress $35 \mathrm{MPa}$; 2, axial stress $45 \mathrm{MPa}$; 3 , axial stress $55 \mathrm{MPa}$; 4 , axial stress $65 \mathrm{MPa}$.

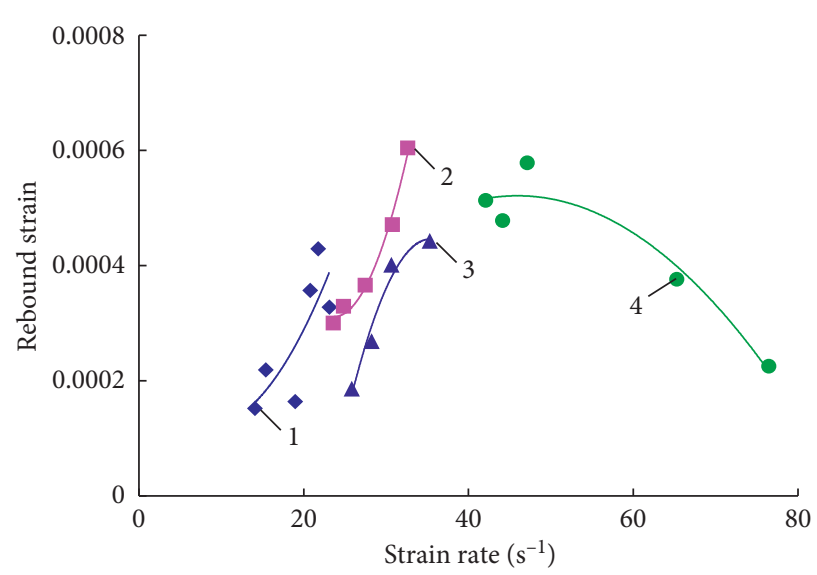

FIGURE 10: Relation between rebound strain and strain rate. 1, axial stress $35 \mathrm{MPa}$; 2, axial stress $45 \mathrm{MPa}$; , axial stress $55 \mathrm{MPa}$; , axial stress $65 \mathrm{MPa}$.

as well as the elastic deformation. When the dynamic stress drops to be less than the internally stored elastic force, part of the elastic deformation recovers, namely, the phenomenon of resilient strain appears.

However, the resilient strain decreases with the increasing strain rate under the static axial stress of $65 \mathrm{MPa}$. The main reason is that the macrofractures have occurred in the specimen under this static axial stress; as a consequence, the ability to resist external impact of rock reduces because of the developing connecting microcracks. With the increase of the strain rate, the damage of specimen increases, the inner stored elastic energy and elastic deformation decreases. Therefore, when the dynamic stress drops to be less than the internally preexisted elastic force, the resilient strain will reduce.

3.5. Law of Dynamic Peak Stress. Figure 11 shows the relationship between dynamic peak stress and strain rate under high static stress and frequent dynamic disturbance. The dynamic peak stress reduces with the increasing strain 


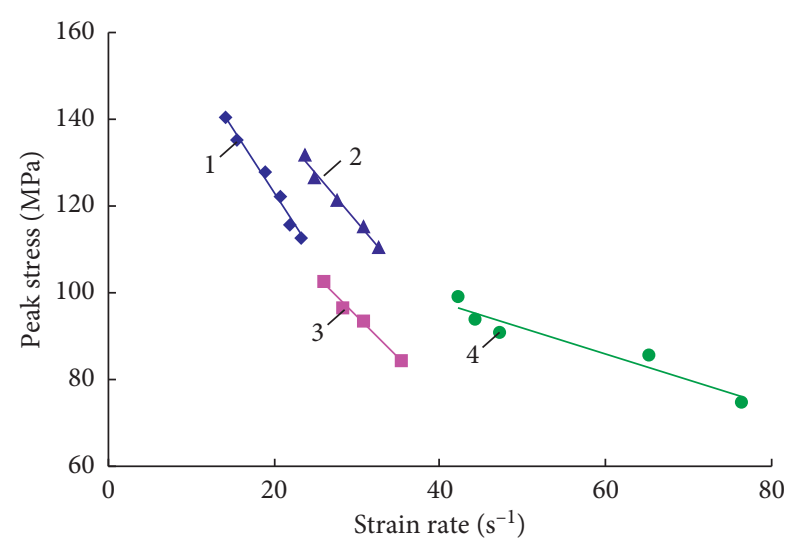

FIGURE 11: Relation between dynamic peak stress and strain rate. 1 , axial stress $35 \mathrm{MPa}$; 2, axial stress $45 \mathrm{MPa}$; , axial stress $55 \mathrm{MPa}$; 4 , axial stress $65 \mathrm{MPa}$.

rate in a certain static axial stress. The strain rate increases with the times of dynamic disturbance, corresponding to the aggravation of damage of rock; thus, the ability of rock to resist external dynamic disturbance reduces.

Figure 11 also shows that dynamic peak stress decreases on the whole with the increasing static axial stress. The main reason is that high prestatic stress makes the status of internal microcracks change in some degrees, such as germination and extension of new microcracks, which prompt rock to rupture in the macroscopic direction.

With the increasing strain rate, the reductive speed of dynamic peak stress is comparatively faster under the static axial stress of $35 \mathrm{MPa}, 45 \mathrm{MPa}$, and $55 \mathrm{MPa}$. This indicates that the static axial stress loaded in advance makes the extension of internal microcracks in the initial stage; consequently, the specimen becomes more sensitive to dynamic disturbance, and dynamic strength decreases quickly because of the rapid development and expansion of microcracks. However, the reductive speed of dynamic peak stress is relatively slow with the rising strain rate under the static axial stress of $65 \mathrm{MPa}$. This is because the microcracks in the specimen are more developed under this higher preaxial stress; the dynamic peak stress has been in a low state, and the strain rate rises faster with the increasing times of dynamic disturbance. The specimen is in a critical state of macroscopical rupture in which dynamic strength reduces drastically under the higher prestatic axial compressive stress.

3.6. Law of Dynamic Deformation Modulus. The computational method of dynamic deformation modulus under high static stress and frequent dynamic disturbance has not been defined clearly so far. At present, secant modulus, the second category of secant modulus [43], and deformation modulus of the loading section [44] are adopted to express dynamic deformation modulus. In order to reduce the errors or discreteness and reflect the variation of deformation in the loading phase under dynamic disturbance, an average of the three types of modulus is used as a dynamic deformation modulus of rock. The method of the determination of the average is shown in Figure 12.

The calculation formula (5) of dynamic deformation modulus can be derived from Figure 12:

$$
E_{d}=\frac{1}{3}\left(E_{1}+E_{2}+E_{3}\right)=\frac{1}{3}\left[\frac{\sigma_{d 50}}{\varepsilon_{d 50}}+\frac{\sigma_{d}-\sigma_{d 50}}{\varepsilon_{d}-\varepsilon_{d 50}}+\tan \alpha\right],
$$

where $E_{1}, E_{2}, E_{3}$, and $E_{d}$ are the secant modulus, the second category of secant modulus, the deformation modulus of the loading section, and the dynamic deformation modulus, respectively; $\sigma_{d}$ is the peak stress, while $\sigma_{d 50}$ is the half of peak stress; $\varepsilon_{d}$ is the peak strain, while $\varepsilon_{d 50}$ is the corresponding strain of $\sigma_{d 50} ; \alpha$ is the angle between tangent line of the point of $\sigma_{d 50}$ and $\varepsilon$-axis.

In order to verify the rationality of formula (5) to determine the dynamic deformation modulus of rocks, the values of $E_{1}, E_{2}, E_{3}$, and $E_{d}$ were compared and analyzed, as shown in Figure 13.

In Figure 13, the dynamic deformation modulus of rock is determined by four methods, and they all decrease with the increase of accumulative impact times. By analyzing the linear fitting formula of dynamic deformation modulus, it is found that $E_{d}$ has the best fitting effect, and its fitting parameter value is 0.943 . It shows that the discreteness of rock deformation modulus can be effectively reduced by using formula (5) to calculate dynamic deformation modulus of rock. At the same time, $E_{1}, E_{2}$, and $E_{3}$ can only reflect the deformation modulus of the rock, which is the deformation modulus at a certain stage before the peak stress of the dynamic stress-strain curve. Therefore, the error is large when it is used to measure the dynamic deformation modulus of the rock in the whole stage before the dynamic peak stress. However, the method to determine dynamic deformation modulus of rock in Figure 13 and formula (5) comprehensively considers all stages, which can effectively reflect the deformation characteristics of rock under dynamic impact load in the whole stage. From the above, the method of calculating dynamic deformation modulus of rock in Figure 13 and formula (5) are reasonable. Therefore, this method is selected to calculate dynamic deformation modulus of rock and analyze the relationship between the calculated value and strain rate.

Figure 14 shows the relationship between dynamic deformation modulus and strain rate under the static axial stress of $35 \mathrm{MPa}, 45 \mathrm{MPa}, 55 \mathrm{MPa}$, and $65 \mathrm{MPa}$. Dynamic deformation modulus decreases with the increase of the strain rate under a certain static axial compressive stress, and its reductive tendency is linear. The increase of the strain rate means that the increase of deformation velocity and the increase of extension, connection, and generation of internal microcracks. As a result, dynamic strength rapidly reduces in a constant dynamic disturbance, and deformation is more easily generated.

Figure 14 also shows that dynamic deformation modulus decreases on the whole with the increasing static axial stress. It indicates that the ability of resisting external dynamic disturbance is affected under a different high static stress. 


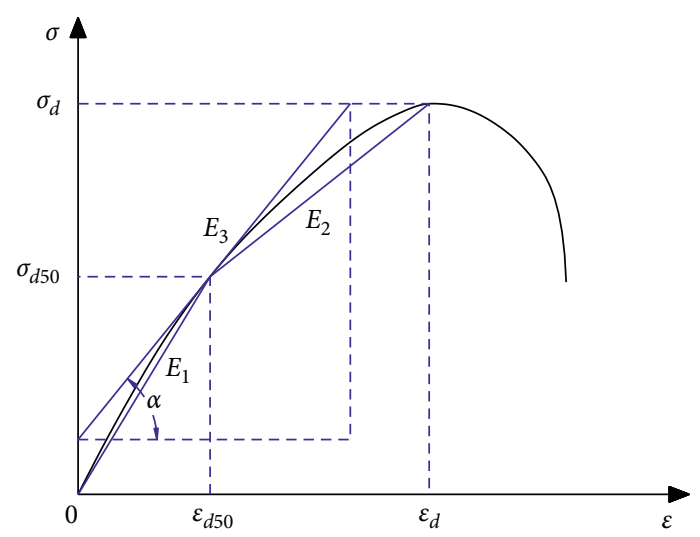

FIGURE 12: Sketch of definition of rock dynamic deformation modulus.

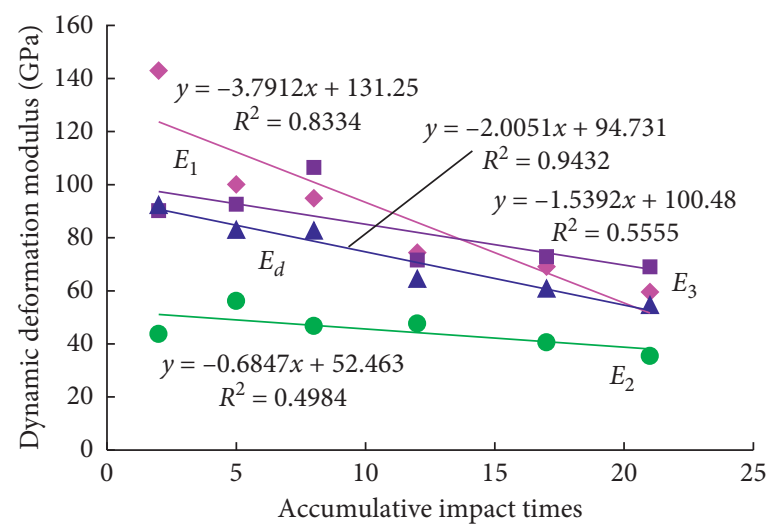

Figure 13: Comparison analysis diagram of calculated values of $E_{1}, E_{2}, E_{3}$, and $E_{d}$.

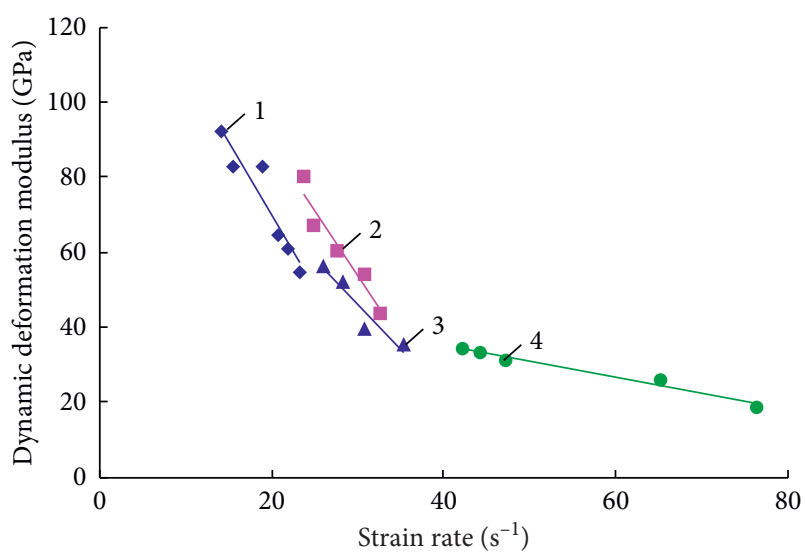

FIGURe 14: Relation between dynamic deformation modulus and strain rate. 1 , axial stress $35 \mathrm{MPa}$; 2, axial stress $45 \mathrm{MPa}$; , axial stress $55 \mathrm{MPa}$; , axial stress $65 \mathrm{MPa}$.

The higher the prestatic axial stress is, the more the microcracks in specimen generated, the weaker the ability of resisting external dynamic disturbance becomes. The constringent strain is larger under the same dynamic disturbance; namely, the strain rate is bigger, which means the dynamic deformation modulus is smaller in the meantime.
3.7. Relationship between Accumulative Times of Dynamic Disturbance and Prestatic Axial Stress. Figure 15 is the relationship between accumulative times of dynamic disturbance and high prestatic axial stress under high static stress and frequent dynamic disturbance. It shows that the times of dynamic disturbance decrease with the increase of prestatic axial stress. This indicates that a different static axial compressive stress will cause different degrees and characteristics of damage of rock. Thus, the dynamic strength of rock decreases, as well as the ability of resisting dynamic disturbance.

Through polynomial fitting to the accumulative impact times of dynamic disturbance and axial stress in Figure 15, the relationship of a quadratic polynomial with one variable can be obtained. And the value of fitting $R^{2}$ is 0.9966 , so the fitting effect is relatively better. The relation of accumulative dynamic disturbance times and static axial stress is defined as formula (6), which is used to predict the times of dynamic disturbance that the rock can withstand in a certain static axial compressive stress and dynamic disturbance produced by a certain air pressure:

$$
\left\{\begin{array}{l}
N=a \sigma^{2}+b \sigma+c, \\
\sigma=40 \% \sim 85 \% \sigma_{c} \\
P_{d}=0.4 \mathrm{MPa}
\end{array}\right.
$$




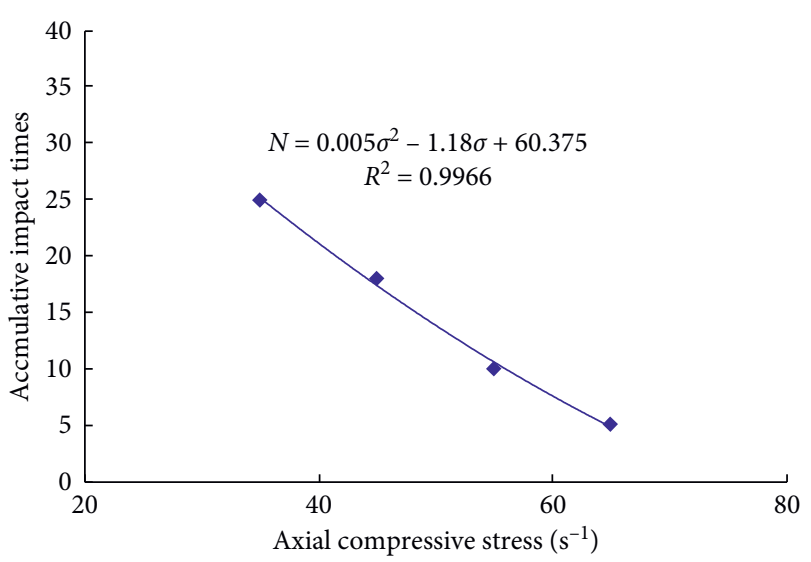

FIGURE 15: Relation between accumulative impact times and the axial stress.

where $a, b$, and $c$ are the constants that needed to be determined by means of test; $N$ and $\sigma$ are variables and expresses accumulative impact times and static axial stress, respectively; $\sigma_{c}$ is the uniaxial compressive strength of rock sample; and $P_{d}$ is the impact load.

\section{Conclusions}

(1) The dynamic stress before dynamic peak stress increases with the increase of dynamic strain in two variational trends of linearity and nonlinearity under a different static axial stress. In addition, with the increasing impact times, the resilient deformation appears in different degrees after dynamic peak stress.

(2) The strain rate of rock is approximately constant in the process of each impact and increases linearly with the increase of times of dynamic disturbance.

(3) With the increase of the strain rate, the maximum strain rises. When prestatic axial stress does not make the inner microcracks connect, both the strength of rock and the inner stored elastic energy are relatively large; therefore, both the restorable elastic deformation and resilient strain are relatively large in later period of unloading.

(4) Both the dynamic peak stress and dynamic deformation modulus reduce with the increase of the strain rate, which indicates that damage of rock is aggravated with the increase of the strain rate. The inner microcracks undergo the phases of germination, extension, and connection, so the dynamic impact strength decreases gradually, and the rock appears macroscopical destroy eventually.

(5) When the static axial stress rises, accumulative times of dynamic disturbance reduce obviously, and the relation between them is a quadratic equation with one variable.

\section{Data Availability}

The data used to support the findings of this study are available from the corresponding author upon request.

\section{Conflicts of Interest}

The authors declare that they have no conflicts of interest.

\section{Authors' Contributions}

The paper was written by Chun Wang. The experiment scheme, data analysis, and preliterature research were carried out by Chun Wang and Lu-ping Cheng. The experiments were carried out by Chun Wang under the help of Cheng Wang, Zhu-qiang Xiong, Shi-ming Wei, Yuan Chen, Tao Liu, and Yong-heng Wei. Li-zhong Tang directed this paper.

\section{Acknowledgments}

The authors are thankful for the financial support from the Key Scientific Research Project of Colleges and Universities of Henan Province under Grant 18A440014, the Doctoral Foundation of Henan Polytechnic University under Grant 672707, the Key Laboratory Open Foundation of Henan Polytechnic University under Grant SJF201802, the National Natural Science Foundation of China under Grant 51674099, the Key Research and Development and Promotion of Special (Science and Technology) Project of Henan Province under Grant 192102310247, and the Exploration of Youth Innovation Foundation of Henan Polytechnic University under Grant NSFRF180321.

\section{References}

[1] Y. T. Zhang, X. L. Ding, S. L. Huang, Y. Qin, P. Li, and Y. J. Li, "Field measurement and numerical simulation of excavation damaged zone in a 2000m-deep cavern," Geomechanics and Engineering, vol. 16, no. 4, pp. 399-413, 2018.

[2] F.-Q. Gong, Y. Luo, X.-B. Li, X.-F. Si, and M. Tao, "Experimental simulation investigation on rockburst induced by spalling failure in deep circular tunnels," Tunnelling and Underground Space Technology, vol. 81, pp. 413-427, 2018.

[3] X. Li, Z. Zhou, T.-S. Lok, L. Hong, and T. Yin, "Innovative testing technique of rock subjected to coupled static and dynamic loads," International Journal of Rock Mechanics and Mining Sciences, vol. 45, no. 5, pp. 739-748, 2008.

[4] S. Mishra, A. Khetwal, and T. Chakraborty, "Dynamic characterisation of gneiss," Rock Mechanics and Rock Engineering, vol. 52, no. 1, pp. 61-81, 2019.

[5] Z. L. Wang, N. C. Tian, J. G. Wang, J. C. Liu, and L. Hong, "Experimental study on damage mechanical characteristics of heat-treated granite under repeated impact," Journal of $\mathrm{Ma}$ terials in Civil Engineering, vol. 30, no. 11, article 04018274, 2018.

[6] Z.-Q. Yin, X.-B. Li, J.-F. Jin, X.-Q. He, and K. Du, "Failure characteristics of high stress rock induced by impact disturbance under confining pressure unloading," Transactions of Nonferrous Metals Society of China, vol. 22, no. 1, pp. 175-184, 2012.

[7] P. Feng, F. Dai, Y. Liu, N.-W. Xu, and H.-B. Du, "Coupled effects of static-dynamic strain rates on the mechanical and fracturing behaviors of rock-like specimens containing two unparallel fissures," Engineering Fracture Mechanics, vol. 207, pp. 237-253, 2019. 
[8] Z. Ye, X. Li, X. Liu, C. Ma, and T. Yin, "Testing studies on rock failure modes of statically loads under dynamic loading," Transactions of Tianjin University, vol. 14, no. 1, pp. 530-535, 2008.

[9] D. D. Ma, Q. Y. Ma, Z. M. Yao, P. Yuan, and R. R. Zhang, "Dynamic mechanical properties and failure mode of artificial frozen silty clay subject to one-dimensional coupled static and dynamic loads," Advances in Civil Engineering, vol. 2019, Article ID 4160804, 9 pages, 2019.

[10] X.-B. Li, Y.-J. Zuo, W.-H. Wang, C.-D. Ma, and Z.-L. Zhou, "Constitutive model of rock under static-dynamic coupling loading and experimental investigation," Transactions of Nonferrous Metals Society of China, vol. 16, no. 3, pp. 714-719, 2006.

[11] J. Z. Liu, J. Y. Xu, X. C. Lv, D. H. Zhao, and B. L. Leng, "Experimental study on dynamic mechanical properties of amphibolites, sericite-quartz schist and sandstone under impact loadings," International Journal of Nonlinear Sciences and Numerical Simjulation, vol. 13, no. 2, pp. 209-217, 2012.

[12] X.-B. Li, Z.-L. Zhou, and Y.-S. Zhao, "Approach to minish scattering of results for split Hopkinson pressure bar test," Journal of Central South University of Technology, vol. 14, no. 3, pp. 404-407, 2007.

[13] Q. Z. Wang, W. Li, and X. L. Song, "A method for testing dynamic tensile strength and elastic modulus of rock materials using SHPB," Pure and Applied Geophysics, vol. 163, no. 5-6, pp. 1091-1100, 2006.

[14] X.-B. Li, L. Hong, T.-B. Yin, Z.-L. Zhou, and Z.-Y. Ye, "Relationship between diameter of split Hopkinson pressure bar and minimum loading rate under rock failure," Journal of Central South University of Technology, vol. 15, no. 2, pp. 218-223, 2008.

[15] S. Kinoshita, K. Sato, and M. Kawakita, "On the mechanical behavior of rocks under impulsive loading," Bulletin of the Faculty of Engineering Hokkaido University, vol. 8, no. 3, pp. 51-62, 1977.

[16] U. S. Lindholm, L. M. Yeakley, and A. Nagy, "The dynamic strength and fracture properties of dresser basalt," International Journal of Rock Mechanics and Mining Sciences and Geomechanics Abstracts, vol. 11, no. 5, pp. 181-191, 1974.

[17] J. S. Green and R. D. Perkins, "Uniaxial compression tests at varying strain rates on three geologic materials," in Proceedings of the 10th Symposium on Basic and Applied Rock Mechanics, pp. 35-52, A. I. M. E, New York, NY, USA, June 1970.

[18] W. A. Olsson, "The compressive strength of tuff as a function of strain rate from $10^{-6}$ to $10^{3} / \mathrm{sec}$," Journal of Rock Mechanics and Mining Sciences \& Geomechanics Abstracts, vol. 28, no. 1, pp. 115-118, 1991.

[19] D. E. Grady, R. E. Hollenbach, J. F. Callender, and K. W. Schuler, "Strain rate dependence in dolomite inferred from impact and static compression studies," Journal of Geophysical Research, vol. 82, no. 8, pp. 1325-1333, 1982.

[20] D. P. Yale, R. Mobil, and W. H. Jamieson, "Static and dynamic rock mechanical properties in the Hugoton and Panoma fields, Kansas," in Proceedings of the SPE Mid-continent Gas Symposium, pp. 209-219, Amarillo, TX, USA, May 1994.

[21] W. L. Vanheerden, "General relations between static and dynamic moduli of rocks," International Journal of Rock Mechanics and Mining Sciences and Geomechanics Abstracts, vol. 24, no. 6, pp. 381-385, 1987.

[22] K. Du, M. Tao, X. B. Li, and J. Zhou, "Experimental study of slabbing and rockburst induced by true-triaxial unloading and local dynamic disturbance," Rock Mechanics and Rock Engineering, vol. 49, no. 9, pp. 3437-3453, 2016.

[23] K. Du, R. Su, M. Tao, C. Yang, A. Momeni, and S. Wang, "Specimen shape and cross-section effects on the mechanical properties of rocks under uniaxial compressive stress," Bulletin of Engineering Geology and the Environment, pp. 1-14, 2019.

[24] S. Wang, X. Li, K. Du, S. Wang, and M. Tao, "Experimental study of the triaxial strength properties of hollow cylindrical granite specimens under coupled external and internal confining stresses," Rock Mechanics and Rock Engineering, vol. 51, no. 7, pp. 2015-2031, 2018.

[25] Y. H. Cheng and W. J. Yang, "Influence of microscopic parameters on the stress-strain relation in rocks," Advances in Civil Engineering, vol. 2018, Article ID 7050468, 7 pages, 2018.

[26] Y.-Y. Tan, X. Yu, D. Elmo, L.-H. Xu, and W.-D. Song, "Experimental study on dynamic mechanical property of cemented tailings backfill under SHPB impact loading," International Journal of Minerals, Metallurgy, and Materials, vol. 26, no. 4, pp. 404-407, 2019.

[27] M. Tao, H. Zhao, X. Li, X. Li, and K. Du, "Failure characteristics and stress distribution of pre-stressed rock specimen with circular cavity subjected to dynamic loading," Tunnelling and Underground Space Technology, vol. 81, pp. 1-15, 2018.

[28] A. Manouchehrian and M. Cai, "Analysis of rockburst in tunnels subjected to static and dynamic loads," Journal of Rock Mechanics and Geotechnical Engineering, vol. 9, no. 6, pp. 1031-1040, 2017.

[29] X. Li, C. Li, W. Cao, and M. Tao, "Dynamic stress concentration and energy evolution of deep-buried tunnels under blasting loads," International Journal of Rock Mechanics and Mining Sciences, vol. 104, pp. 131-146, 2018.

[30] L. Hu, K. Ma, X. Liang et al., "Experimental and numerical study on rockburst triggered by tangential weak cyclic dynamic disturbance under true triaxial conditions," Tunnelling and Underground Space Technology, vol. 81, pp. 602-618, 2018.

[31] X. Li and L. Weng, "Numerical investigation on fracturing behaviors of deep-buried opening under dynamic disturbance," Tunnelling and Underground Space Technology, vol. 54, pp. 61-72, 2016.

[32] L. L. Niu, W. C. Zhu, Z. Cheng, K. Guan, and T. Qin, "Numerical simulation on excavation-induced damage of rock under quasi-static unloading and dynamic disturbance," Environmental Earth Sciences, vol. 76, no. 17, pp. 614-628, 2017.

[33] W. C. Zhu, Y. Bai, X. B. Li, and L. L. Niu, "Numerical simulation on rock failure under combined static and dynamic loading during SHPB tests," International Journal of Impact Engineering, vol. 49, pp. 142-157, 2012.

[34] W. C. Zhu, Z. H. Li, L. Zhu, and C. A. Tang, "Numerical simulation on rockburst of underground opening triggered by dynamic disturbance," Tunnelling and Underground Space Technology, vol. 25, no. 5, pp. 587-599, 2010.

[35] F. Li, M. X. Bi, J. Tian, and S. H. Fang, "The dynamic damage mechanisms and failure modes of coal-rock masses under the action of high order P-waves," Shock and Vibration, vol. 2018, Article ID 5386123, 11 pages, 2018.

[36] W. Wang, H. M. Li, and H. L. Gu, "Experimental study of strength characteristics of water-saturated coal specimens under 3D coupled static-dynamic loadings," Chinese Journal of Rock Mechanics and Engineering, vol. 36, no. 10, pp. 2406-2411, 2017. 
[37] X. B. Li and D. S. Gu, Rock Impact Dynamics, Changsha: Central South University of Technology Press, Changsha, Hunan, China, 1994.

[38] X. B. Li, Z. L. Zhou, and W. H. Wang, "Construction of ideal striker for SHPB device based on FEM and neural network," Chinese Journal of Rock Mechanics and Engineering, vol. 24, no. 23, pp. 4215-4219, 2005, in Chinese.

[39] X. B. Li, Z. L. Zhou, and Z. Y. Ye, "Study of rock mechanical characteristics under coupled static and dynamic loads," Chinese Journal of Rock Mechanics and Engineering, vol. 27, no. 7, pp. 1387-1395, 2008.

[40] X. B. Li, T. S. Lok, J. Zhao, and P. J. Zhao, "Oscillation elimination in the Hopkinson bar apparatus and resultant complete dynamic stress-strain curves for rocks," International Journal of Rock Mechanics and Mining Sciences, vol. 37, no. 7, pp. 1055-1060, 2000.

[41] Z. L. Zhou, Experimental and Mechanical Properties Research of Rock under Dynamic and Static Combined Loading, Changsha: Central South University of Technology Press, Changsha, China, 2007.

[42] Y. J. Zuo, X. B. Li, and C. A. Tang, "Experimental investigation on failure of rock subjected to 2D dynamic-static coupling loading," Chinese Journal of Rock Mechanics and Engineering, vol. 25, no. 9, pp. 1809-1820, 2006, in Chinese.

[43] K. Behzadafshar, M. E. Sarafraz, M. Hasanipanah, S. F. F. Mojtahedi, and M. M. Tahir, "Proposing a new model to approximate the elasticity modulus of granite rock samples based on laboratory tests results," Bulletin of Engineering Geology and the Environment, vol. 78, no. 3, pp. 1527-1536, 2019.

[44] A. E. Aladejare and Y. Wang, "Estimation of rock mass deformation modulus using indirect information from multiple sources," Tunnelling and Underground Space Technology, vol. 85, pp. 76-83, 2018. 


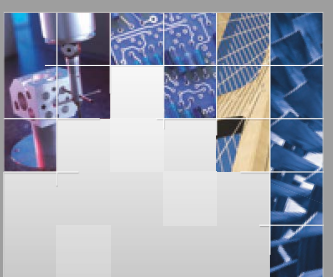

\section{Enfincering}
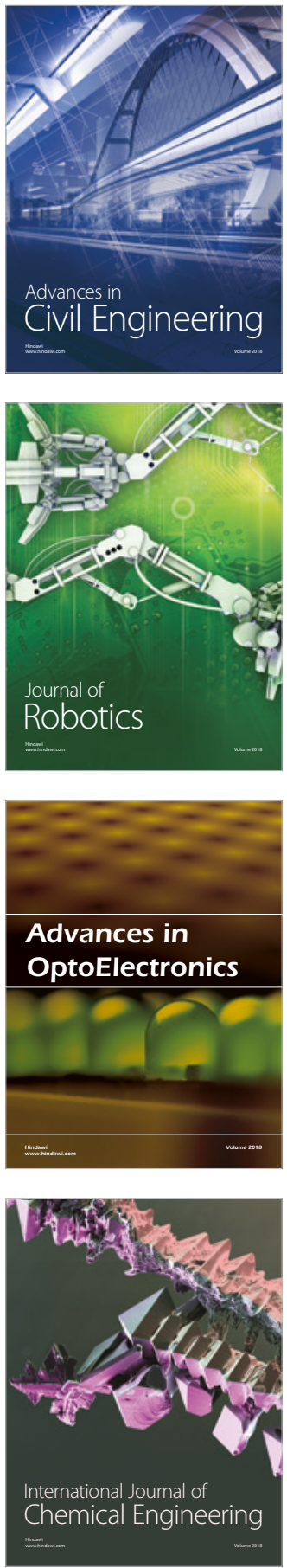

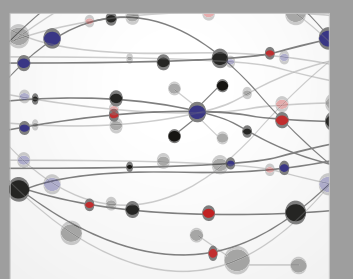

\section{Rotating \\ Machinery}

The Scientific World Journal

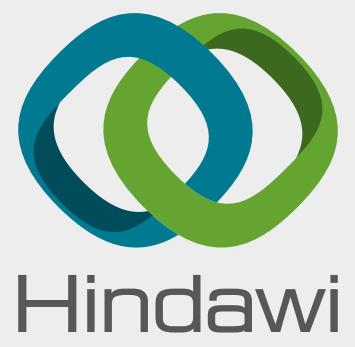

Submit your manuscripts at

www.hindawi.com
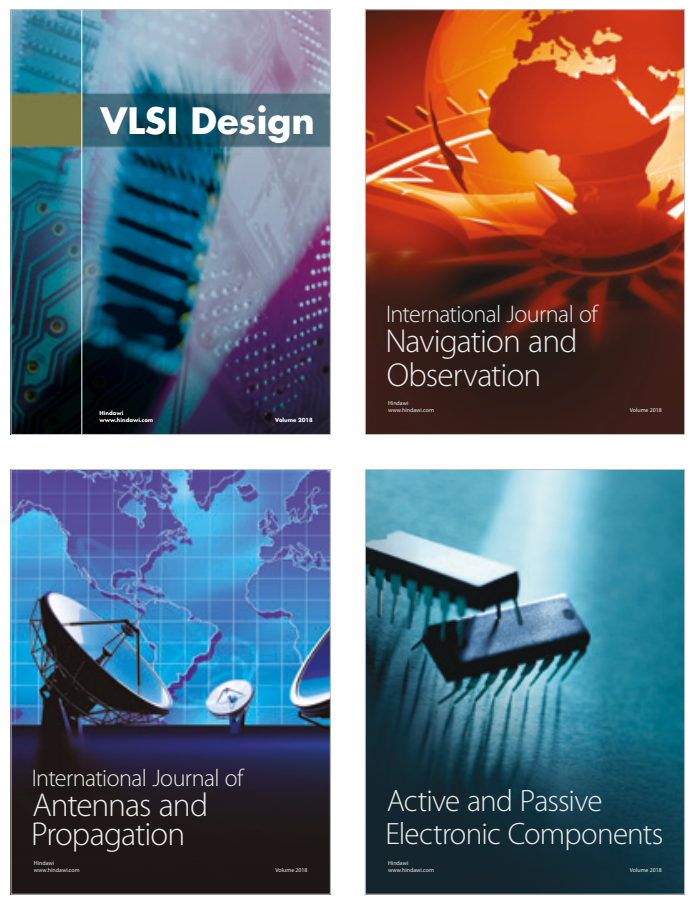
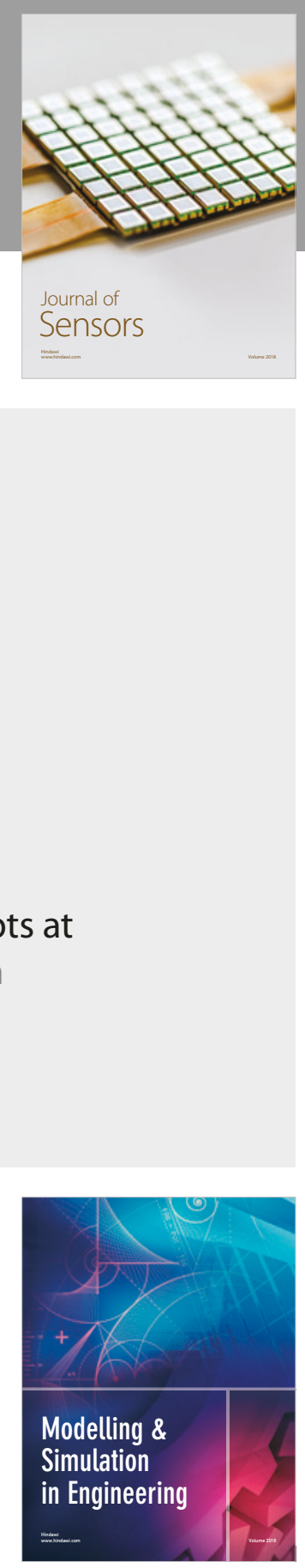

\section{Advances \\ Multimedia}
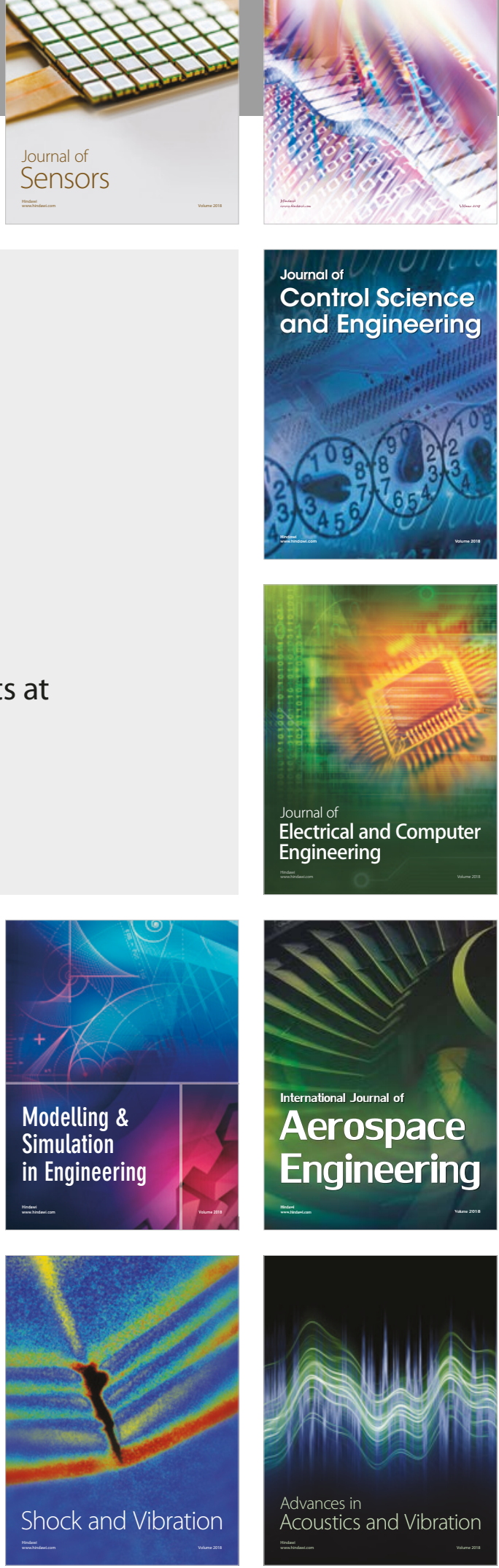